\title{
Mechanism and epidemiology of paediatric finger injuries at Prince of Wales Hospital in Hong Kong
}

\author{
WH Liu *, Johann Lok, MS Lau, YW Hung, Clara WY Wong, WL Tse, PC Ho
}

\section{A B S T R A C T}

Objectives: To determine the mechanism and epidemiology of paediatric finger injuries in Hong Kong during 2003-2005 and 2010-2012.

Design: Comparison of two case series.

Setting: University-affiliated teaching hospital, Hong Kong.

Patients: This was a retrospective study of two cohorts of children (age, 0 to 16 years) admitted to Prince of Wales Hospital with finger injuries during two 3-year periods. Comparisons were made between the two groups for age, involved finger(s), mechanism of injury, treatment, and outcome. Telephone interviews were conducted for parents of children who sustained a crushing injury of finger(s) by door.

Results: A total of 137 children (group A) were admitted from 1 January 2003 to 31 December 2005, and 109 children (group B) were admitted from 1 January 2010 to 31 December 2012. Overall, the mechanisms and epidemiology of paediatric finger injuries were similar between groups $\mathrm{A}$ and B. Most finger injuries occurred in children younger than 5 years (group A, 56\%; group B, 76\%) and in their home (group A, 67\%; group B, 69\%). The most common mechanism was crushing injury of finger by door (group A, 33\%; group B, 41\%) on the hinge side (group A, 63\%; group B, 64\%). The right hand was most commonly involved. The door was often closed by another child (group A, 37\%; group B, 23\%) and the injury often occurred in the presence of adults
This article was published on 8 May 2015 at www.hkmj.org.
$39 \%$ ). Fractures occurred in $24 \%$ and $23 \%$ in groups $A$ and $B$, respectively. Traumatic finger amputation requiring replantation or revascularisation occurred in $12 \%$ and $10 \%$ in groups $\mathrm{A}$ and $\mathrm{B}$, respectively.

Conclusions: Crushing injury of finger by door is the most common mechanism of injury among younger children and accounts for a large number of hospital admissions. Serious injuries, such as amputations leading to considerable morbidity, can result. Crushing injury of finger by door occurs even in the presence of adults. There has been no significant decrease in the number of crushing injuries of finger by door in the 5 years between the two studies despite easily available and affordable preventive measures. It is the authors' view that measures aimed at promoting public awareness and education, and safety precautions are needed.
Hong Kong Med J 2015;21:237-42
DOI: $10.12809 / \mathrm{hkmj} 144344$
WH Liu *, MB, BS
J Lok, MB, ChB
MS Lau, MB, ChB
YW Hung, FHKCOS, FHKAM (Orthopaedic Surgery)
CWY Wong, FHKCOS, FHKAM (Orthopaedic Surgery)
WL Tse, FHKCOS, FHKAM (Orthopaedic Surgery)
PC Ho, FHKCOS, FHKAM (Orthopaedic Surgery)

Department of Orthopaedics and Traumatology, Prince of Wales Hospital, The Chinese University of Hong Kong, Shatin, Hong Kong

* Corresponding author: liuwinghong@yahoo.com.hk

This paper was presented at the 27th Annual Congress of the Hong Kong commonest type of injury (group A, 31\%; group B, Society for Surgery of the Hand, 15-16 March 2014, Hong Kong.

New knowledge added by this study

- Similar to other countries, crushing injury of finger by door was the most common cause of paediatric finger injuries in Hong Kong.

- Although many preventive measures are available and easily accessible at low cost, there were no significant differences in injury mechanism and epidemiology between 2003-2005 and 2010-2012.

Implications for clinical practice or policy

- Paediatric crushing injury of finger by door can occur even in the presence of adults. Reinforcement of public education on the use of safety measures, including door modification and precautions in the home, should be conducted to prevent such injuries.

\section{Introduction}

Injuries to the hand and fingers are extremely common in children, yet they can have a significant impact on a child's growth and development. Fingers are used to explore surroundings and perform daily activities such as playing, eating, and homework. 


\section{香港威爾斯親王醫院中兒童手指受傷的原因和 流行病學}

\author{
廖泳康、駱宇漢、劉美璇、洪煜華、黃詠儀、謝永廉、何百昌
}

目的：找出2003-2005年以及2010-2012年期間香港兒童手指受傷的 機制和流行病學。

設計：兩個病例系列的比較。

安排：香港一所大學附屬的教學醫院。

患者：回顧研究分別於兩個三年期的時間內因手指受傷往香港威爾斯 親王醫院求診的兩組兒童患者（年齡介乎 0 至 16 歲）。比較兩組之間 的年齡、涉及的手指、受傷原因、治療以及其結果。對於手指被門夾 傷的病例, 亦會用電話訪問傷者父母受傷的細節。

結果：本研究的兩個三年期分別為2003年1月 1 日至2005年12月 31 日 以及 2010 年 1 月 1 日至 2012 年 12 月 31 日, 於第一個三年期因手指受 傷而入院的有 137 名兒童（甲組），而於第二個三年期因相同原因而 入院的有109名兒童 (乙組)。總體而言, 兩組兒童手指受傷的原因 及流行病學分佈相似。大部分病例發生在5歲以下的兒童身上（甲組 $56 \%$, 乙組 $76 \%$ ），且在家中發生（甲組67\%，乙組69\%）。最常見的

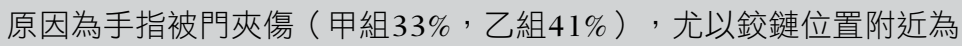
甚（甲組 $63 \%$, 乙組 $64 \%$ ）。意外最常累及右手, 通常是當另一名兒 童把門關上時發生的（甲組 $37 \%$, 乙組 $23 \%$ ）；而意外發生時通常有 成年人在場（甲組 $60 \%$, 乙組 $56 \%$ ）。甲床損傷最常見（甲組 $31 \%$, 乙組 $39 \%$ ）。甲乙兩組的骨折率分別為 $24 \%$ 和 $23 \%$, 而因受傷須截除 手指以及再植或血運重建的比率分別為 $12 \%$ 和 $10 \%$ 。

結論：手指被門夾傷常見於幼童, 並造成大量入院個案, 這種意外可 導致高發病率及嚴重後果, 例如截除手指。即使有成年人在場, 手指 被門夾傷也可能發生。儘管可以透過簡單而又便宜的預防措施來避免 手指被門夾傷, 但本研究發現縱使兩段研究期相隔五年, 同類的意外 並沒有明顯減少。筆者認為必須採取適當的防範措施, 並提高公眾意 識、加強公眾教育來避免同類意外發生。
Restricting children from these activities due to injuries can have immediate short- and long-term detrimental effects on the function of the hand, psychological wellbeing, and quality of life of the children. A 10-year review on the psychological impact on children and adolescents with finger or hand injuries noted that "Hand injuries are common and loss of a dominant hand or opposition is most important [sic]. Self-esteem and skill are associated

BOX. CDARS case finding list of Prince of Wales Hospital
ICD-9-CM code: 2014 ICD-9-CM diagnosis
816: Fracture of one or more phalanges of hand
817: Multiple fractures of hand bones
883: Open wound of finger(s)
885: Traumatic amputation of thumb (complete) [partial]
886: Traumatic amputation of other finger(s) (complete) [partial]
923.3: Contusion of finger
927.3: Crushing injury of finger(s)

Abbreviations: CDARS = Clinical Data Analysis and Reporting System; ICD-9-CM = International Classification of Diseases, 9th Revision, Clinical Modification with hand sensation, appearance, and functions."

Studies by Al-Anazi ${ }^{2}$ and Doraiswamy ${ }^{3}$ have identified crushing injury of finger(s) by door as the main cause of finger injuries in children. However, there has been no local study to identify the main cause of finger injuries in Hong Kong. In 2007, Lau and Ho presented data on the epidemiology of childhood finger injuries (unpublished data; Lau M, Ho PC. 20th Annual Congress of the Hong Kong Society for Surgery of the Hand, Hong Kong, 2007) that supported the findings in other cities. Similar to Al-Anazi ${ }^{2}$ and Doraiswamy, ${ }^{3}$ Lau and Ho found that crushing injury of finger by door was the most common cause of paediatric finger injuries from 2003 to 2005, and recommended various preventive measures.

The present study aimed to compare the previous set of data from 2003 to 2005 reported by Lau and Ho with more recent data obtained from 2010 to 2012. By comparing the epidemiology and mechanisms of finger injuries among local Hong Kong children, we aimed to determine whether there have been any significant changes over the past 5 years.

\section{Methods}

Data of patients admitted to Prince of Wales Hospital from 1 January 2003 to 31 December 2005 (group A) and from 1 January 2010 to 31 December 2012 (group B) were retrieved using the Clinical Data Analysis and Reporting System (CDARS) of the Hospital Authority's Clinical Management System. Children aged 0 to 16 years, and with at least one of the International Classification of Diseases, 9th Revision, Clinical Modification (ICD-9-CM) codes listed in the Box among the top three diagnoses were included in the analysis.

Discharge summaries of all patients were reviewed to identify the mechanisms of finger injuries. For children in whom the mechanism was not immediately discernable from the discharge summary, further clarifications were obtained by telephone interviews with the child's parents, which were conducted in 2006 for group A and in 2013 for group B. For children in whom crushing injury of finger(s) were due to closing doors, additional data were collected by telephone interviews with their parents using a specifically designed questionnaire (Fig 1).

\section{Results}

Group A consisted of 140 children who presented with finger injury to Prince of Wales Hospital from 1 January 2003 to 31 December 2005. Three children from this group were excluded due to coding error. Group B comprised 109 children who presented from 1 January 2010 to 31 December 2012. No 
Crushing injury of the finger and Questionnaire

1. Site of injury:
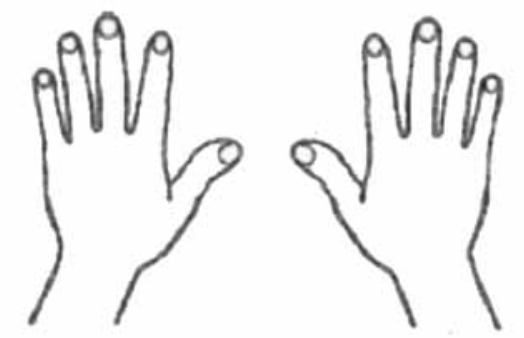

2. Place of injury:
$\square$ Home
$\square$ School
$\square$ Car
$\square$ Others
Unknown

3. Locations of doors causing finger injuries (home):
$\square$ Front door
Bedroom
Kitchen
Toilet
Others
Unknown

4. Side of door:
Hinge
Lock
Middle of a double door
Unknown

5. Who closed the door?
$\square$ Self
$\square$ Child
$\square$ Adult
Spontaneous
Unknown

6. Presence of adult:
Yes
$\square$ No

7. Outcome - Level of satisfaction (0-10):

a. Pain

Please circle the number which best describes your current level of pain

\begin{tabular}{lrlllllllcc}
\hline 0 & 1 & 2 & 3 & 4 & 5 & 6 & 7 & 8 & 9 & 10 \\
No pain & & & & & & & & Worst possible pain
\end{tabular}

b. Daily activity

Please circle the number which best describes your current level of activity

\begin{tabular}{|c|c|c|c|c|c|c|c|c|c|c|}
\hline 0 & 1 & 2 & 3 & 4 & 5 & 6 & 7 & 8 & 9 & 10 \\
\hline \multicolumn{11}{|c|}{ Severely affecting daily activities } \\
\hline
\end{tabular}

c. Cosmesis

Please circle the number which best describes your current level of cosmesis

\begin{tabular}{|c|c|c|c|c|c|c|c|c|c|}
\hline 0 & 2 & 3 & 4 & 5 & 6 & 7 & 8 & 9 & 10 \\
\hline & smesis & & & & & & & No & meti \\
\hline
\end{tabular}

FIG I. Questionnaire on crushing injury of finger by door 
children from this group were excluded.

In both groups, crushing injury of finger by door was the most common cause of injury-45 $(33 \%)$ in group A and $45(41 \%)$ in group B-followed by sports injury, cut, and slip and fall (Table 1). Among children with crushing injury of finger by

TABLE I. Mechanism of injury

\begin{tabular}{lcc}
\hline $\begin{array}{l}\text { Mechanism of } \\
\text { injury }\end{array}$ & \multicolumn{2}{c}{ No. (\%) of patients* } \\
\cline { 2 - 3 } & $\begin{array}{c}\text { Group A (2003- } \\
\text { 2005) [n=137] }\end{array}$ & $\begin{array}{c}\text { Group B (2010- } \\
\text { 2012) [n=109] }\end{array}$ \\
\hline Crush (door) & $45(33)$ & $45(41)$ \\
Sports injury & $34(25)$ & $18(17)$ \\
Cut & $21(15)$ & $15(14)$ \\
\hline Slip and fall & $14(10)$ & $9(8)$ \\
Others & $10(7)$ & $12(11)$ \\
Crush (others) & $12(9)$ & $5(5)$ \\
Unknown & $1(1)$ & $5(5)$ \\
\hline
\end{tabular}

* Because of rounding, not all percentages total 100

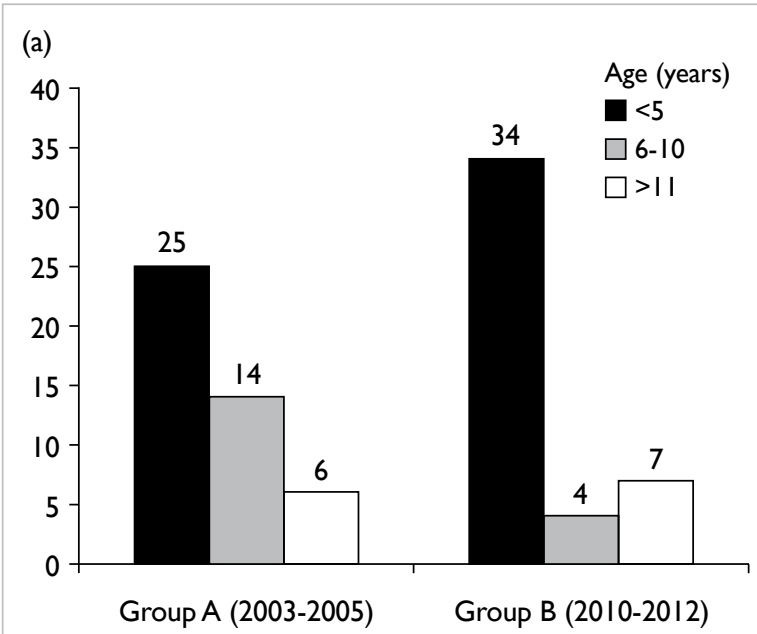

(b)

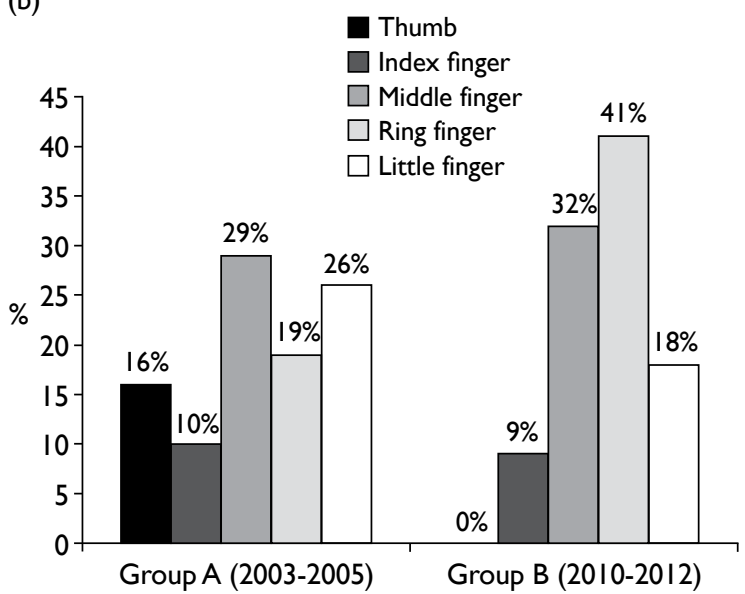

FIG 2. (a) Distribution of children with crushing injury of finger by door by age, and (b) localisation of injury door, younger children were the most commonly injured (Fig 2a). The male-to-female ratio was 1:1.25 in group $A$ and 1.37:1 in group $B$.

In the telephone interviews conducted with the parents of the 45 children who had crushing injury of finger by door, parents of two children in group A and six children in group B could not be contacted. Overall, all the parameters measured were similar between the periods 2003-2005 and 2010-2012. In both groups, most of the fingers involved were from the right hand, with the middle, ring, and little fingers being more commonly affected than the other fingers (Fig 2b).

Most of the injuries occurred at home-29 (67\%) in group A and 27 (69\%) in group B. At home, fingers were most frequently crushed at the hinge side of the door-27 (63\%) in group A and 25 (64\%) in group $\mathrm{B}$-followed by the lock side and the middle

TABLE 2. Telephone interviews of parents of children who had crushing injury of finger by door

\begin{tabular}{|c|c|c|}
\hline & \multicolumn{2}{|c|}{ No. (\%) of patients } \\
\hline & $\begin{array}{c}\text { Group A } \\
(2003-2005) \\
{[n=43]}\end{array}$ & $\begin{array}{c}\text { Group B } \\
(2010-2012) \\
{[n=39]}\end{array}$ \\
\hline \multicolumn{3}{|l|}{ Place of injury } \\
\hline Home & $29(67)$ & $27(69)$ \\
\hline School & $6(14)$ & $5(13)$ \\
\hline Car & $2(5)$ & $0(0)$ \\
\hline Others & $6(14)$ & $7(18)$ \\
\hline \multicolumn{3}{|l|}{ Location of door at home } \\
\hline Front door & $8(19)$ & $6(15)$ \\
\hline Bedroom & $7(16)$ & $12(31)$ \\
\hline Kitchen & $4(9)$ & $0(0)$ \\
\hline Toilet/bathroom & $5(12)$ & $10(26)$ \\
\hline Others & $5(12)$ & $2(5)$ \\
\hline Unknown & $14(33)$ & $9(23)$ \\
\hline \multicolumn{3}{|l|}{ Side of door } \\
\hline Hinge side & $27(63)$ & $25(64)$ \\
\hline Lock side & $14(33)$ & $9(23)$ \\
\hline Middle of a double door & $1(2)$ & $0(0)$ \\
\hline Unknown & $1(2)$ & $5(13)$ \\
\hline \multicolumn{3}{|l|}{ Who closed the door } \\
\hline Self & $8(19)$ & $9(23)$ \\
\hline Another child & $16(37)$ & $9(23)$ \\
\hline Adult & $9(21)$ & $11(28)$ \\
\hline Spontaneous & $9(21)$ & $5(13)$ \\
\hline Unknown & $1(2)$ & $5(13)$ \\
\hline \multicolumn{3}{|l|}{ Presence of adult } \\
\hline Yes & $26(60)$ & $22(56)$ \\
\hline No & $17(40)$ & $17(44)$ \\
\hline
\end{tabular}


of a double door. The doors were frequently closed by another child-16 (37\%) in group A and 9 (23\%) in group B and, in more than half of the cases, occurred even in the presence of adults-26 (60\%) in group A and $22(56 \%)$ in group B (Table 2 ).

The types of injury and their relative frequencies were compared between the groups (Table 3). Among the more common injuries were: nailbed injury-22 (31\%) in group A and 22 (39\%) in group B; fracture-17 (24\%) in group A and 13 (23\%) in group B; and laceration-17 (24\%) in group A and $11(20 \%)$ in group B. Most of the children in both group A (31 [72\%]) and group B (30 [77\%]) required operation. Among the 31 operations in group A, 21 (68\%) were performed under general anaesthesia. By contrast, only 12 (40\%) of the 30 operations in group $\mathrm{B}$ involved general anaesthesia.

Clinical outcomes were assessed when the telephone interviews were conducted, ie, in 2006 for group A and in 2013 for group B. Most children had a good recovery following treatment. Overall, $42(98 \%)$ of children in group A and 37 (94\%) of children in group B reported no pain. Only minor cosmetic problems prevailed in most children, with 34 (79\%) in group A and 35 (89\%) in group B rating their current level of cosmesis over 7 out of 10 (score $10=$ no cosmetic problem). The injuries had minimal adverse effects for most children, with 42 (98\%) in

TABLE 3. Types of injury, surgical intervention, and mode of anaesthesia of children having crushing injury of finger by door

\begin{tabular}{lcc}
\hline & \multicolumn{2}{c}{ No. (\%) of patients } \\
\cline { 2 - 3 } & $\begin{array}{c}\text { Group A } \\
(\mathbf{2 0 0 3 - 2 0 0 5 )}\end{array}$ & $\begin{array}{c}\text { Group B } \\
(\mathbf{2 0 1 0 - 2 0 1 2})\end{array}$ \\
\hline Type of injury & & \\
\hline Nailbed injury & $22(31)$ & $22(39)$ \\
\hline Fracture & $17(24)$ & $13(23)$ \\
\hline Laceration & $17(24)$ & $11(20)$ \\
\hline Amputation & $5(7)$ & $4(7)$ \\
\hline Contusion & $5(7)$ & $3(5)$ \\
\hline Subungual haematoma & $3(4)$ & $3(5)$ \\
\hline Tendon cut & $1(1)$ & 0 \\
\hline Total & $70(100)$ & $56(100)$ \\
\hline Surgical intervention & & \\
\hline Yes & $31(72)$ & $30(77)$ \\
\hline No & $12(28)$ & $9(23)$ \\
\hline Total & $43(100)$ & $39(100)$ \\
\hline Mode of anaesthesia & & \\
\hline Local anaesthesia & $10(32)$ & $18(60)$ \\
\hline General anaesthesia & $21(68)$ & $12(40)$ \\
\hline Total & $31(100)$ & $30(100)$ \\
\hline More tha & & \\
\hline
\end{tabular}

* More than one injury might be reported for a child

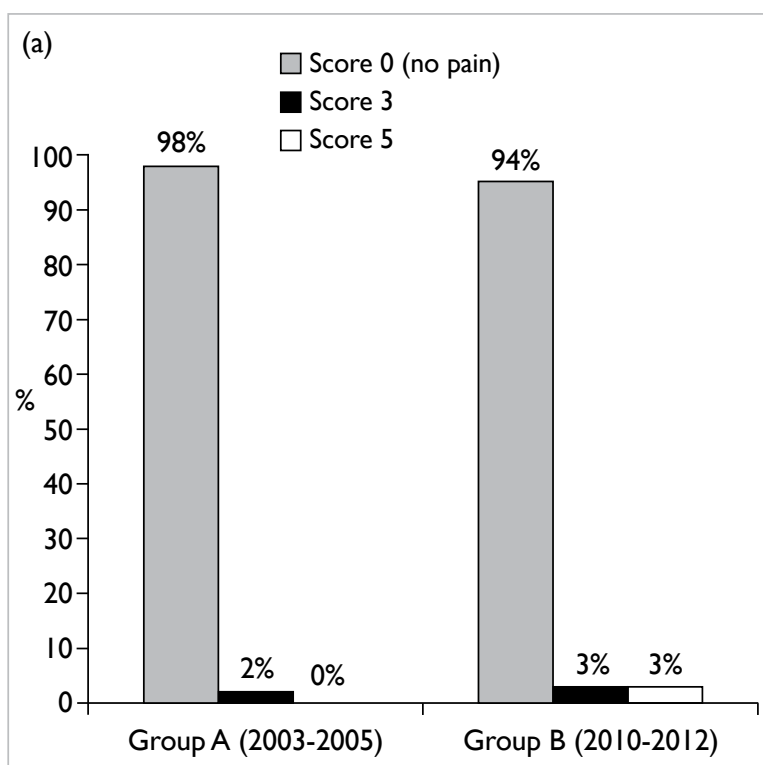

(b)
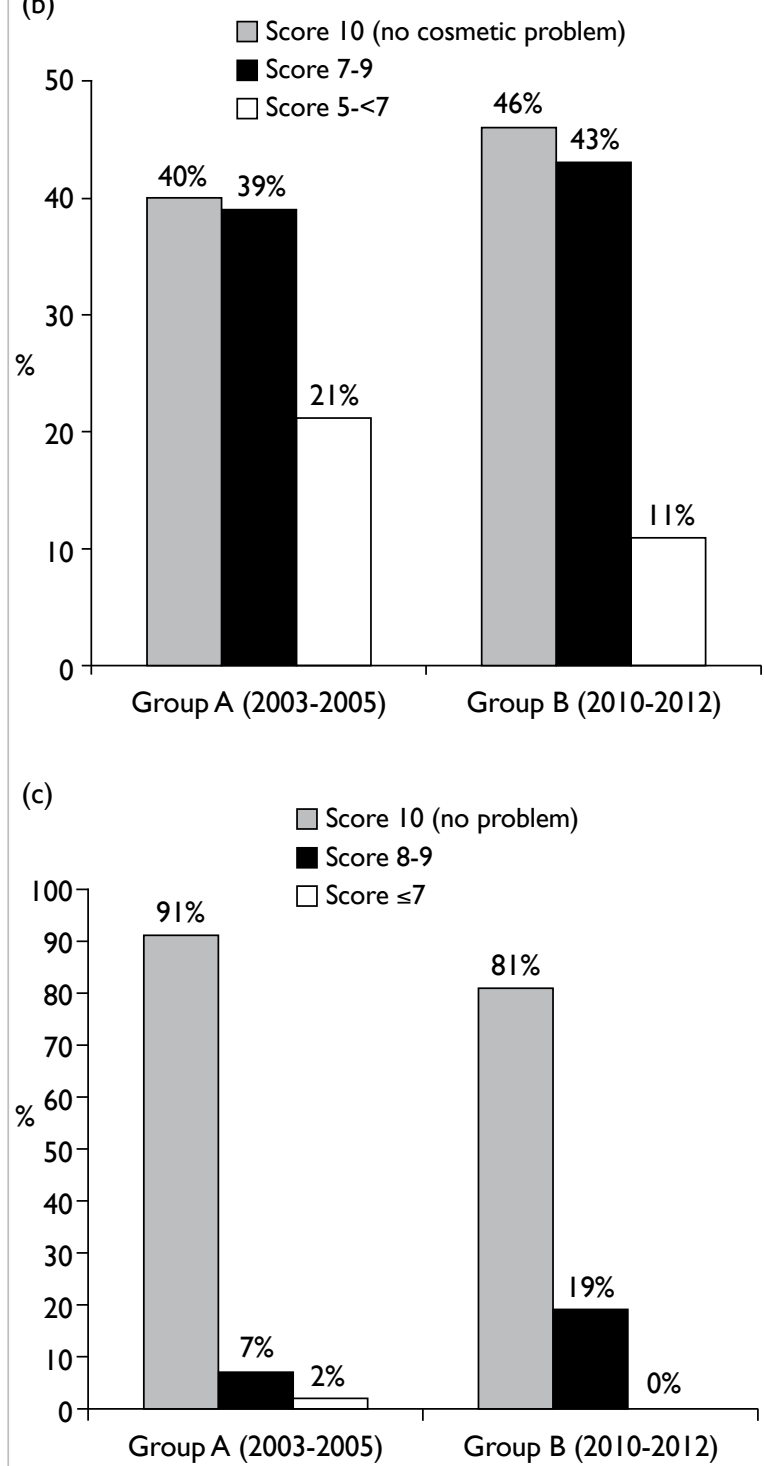

FIG 3. Clinical outcomes assessed by telephone interview: (a) pain, (b) cosmesis, and (c) daily activities 
group A and 39 (100\%) in group B rated their daily activities with a score over 8 (score $10=$ no problem) [Fig 3].

However, five (12\%) children in group A and four $(10 \%)$ children in group B had crushing injury of finger by door resulting in finger amputation. Altogether seven children in groups $\mathrm{A}$ and $\mathrm{B}$ received replantation or revascularisation, one child underwent open reduction and fixation only, and one had a failed replantation due to failure to locate the arteries intra-operatively.

In group $\mathrm{A}$, one child developed thrombosis following replantation of the right ring finger, requiring a subsequent revascularisation procedure 3 days later. This was complicated by hooknail deformity 1 year post-replantation and was subsequently treated by further reconstructive procedures. The levels of satisfaction in terms of appearance and daily function at final follow-up were rated 5 and 3 (out of 10, with 10 means no cosmetic problem and no problem in daily activities), respectively.

\section{Discussion}

Crushing injury of finger by door is common. The true incidence of this type of injury is likely to be higher, as our data were limited to public hospitals so relied on the correct entry of ICD-9-CM codes into the CDARS. Data from the accident and emergency department and private practitioners were not analysed. Furthermore, many minor injuries might have been managed at home and not reported.

Crushing injury of finger by door is not just a local problem. Studies from Saudi Arabia and Glasgow showed that this type of injury accounted for most childhood fingertip injuries in these areas. ${ }^{2,3}$ These injuries consistently occurred at home, with the involved finger being frequently crushed at the hinge side of doors. Younger children were mostly affected. The similarity in epidemiology between the overseas data and our local data can help with recommendations for suitable door safety devices.

In this study, we identified that crushing injury by door was the major cause of paediatric finger injuries leading to hospital admission in both 20032005 and 2010-2012. Although most children were satisfied with the level of pain, cosmesis, and daily function of the injured digit at their final follow-up after treatment, serious injuries involving fractures and amputations occurred in a minority of patients. In addition to the surgical intervention and longterm hospitalisation required, these injuries could further lead to detrimental effects on the children's growth and development.

Our study showed the presence of adults did not reduce the rate of these accidents, since most occurred even in the presence of an adult. This highlights the need for other preventative measures. Many types of safety devices are easily available and affordable in Hong Kong. As the hinge side of doors is the most common side for fingers to be crushed, finger guard devices can be installed to prevent fingers being trapped in the opposing surfaces. Triangular-shaped rubbers, plastic or wooden stoppers can be inserted at the bottom of a door to prevent spontaneous closure. Magnets applied to the back of a door and its opposing wall surface present another equally effective and simple method of preventing unintended door closures. Dampers can be set up to reduce the speed of closing doors, thereby decreasing the force exerted on trapped fingers. The use of automatic doors should be avoided.

Yet, despite the easy availability and accessibility of these safety devices, there has been no significant change or improvement in terms of incidence and morbidity of children with crushing injury of fingers by door admitted to Prince of Wales Hospital in the 5-year period between 2003-2005 and 2010-2012. Thus, we should promote public awareness about this type of injury and provide more educational programmes on safety precautions in order to reduce the incidence of crushing injury of finger by door.

\section{Conclusions}

Crushing injury of finger by door accounts for the most common cause of paediatric finger injury requiring hospitalisation in Hong Kong. These injuries frequently result in hospital admission and surgical intervention, with considerable morbidity and high treatment cost. Crushing injury of finger by door occurs even in the presence of adults. Despite the easily available and affordable preventative measures in Hong Kong, our comparison revealed no significant difference in the incidence, nature, and severity of these domestic injuries between the years 2003-2005 and 2010-2012. Thus, it is our view that more effort should be invested into raising public awareness and education about these preventable injuries and to promote prevention measures.

\section{References}

1. Stoddard F, Saxe G. Ten-year research review of physical injuries. J Am Acad Child Adolesc Psychiatry 2001;40:112845.

2. Al-Anazi AF. Fingertip injuries in paediatric patientsexperiences at an emergency centre in Saudi Arabia. J Pak Med Assoc 2013;63:675-9.

3. Doraiswamy NV. Childhood finger injuries and safeguards. Inj Prev 1999;5:298-300. 